\title{
Progressive Neurological Deterioration in Mild Traumatic Brain Injury with Acute Intracranial Hemorrhage: A Single Center, Retrospective Observational Comparative Study
}

\author{
Jung-hoon Kim¹, Jae-Sung Park ${ }^{1}$, Byung-chul Son ${ }^{1}$, Sin-soo Jeon ${ }^{1}$, Kwan-Sung Lee ${ }^{1}$, Yong Sam Shin ${ }^{1}$, \\ Jin-gyu Choi ${ }^{2}$ \\ ${ }^{1}$ Department of Neurosurgery, Seoul St. Mary's Hospital, College of Medicine, The Catholic University of Korea, Seoul, \\ ${ }^{2}$ Department of Neurosurgery, Yeouido St. Mary's Hospital, College of Medicine, The Catholic University of Korea, Seoul, \\ Republic of Korea
}

Corresponding author:

Jin-gyu Choi

Department of Neurosurgery,

Yeouido St. Mary's Hospital,

College of Medicine, The Catholic

University of Korea, 10, 63-ro,

Yeongdeungpo-gu, Seoul 07345,

Republic of Korea

Tel: +82-2-3779-1058

Fax: +82-2-786-5809

E-mail: nschoi@catholic.ac.kr

Received: July 7, 2018

Revised: July 17, 2018

Accepted: July 23, 2018
Objective: To assess the rate of acute neurologic aggravation of mild traumatic brain injury (TBI) patients, and to compare the deterioration frequency between categorized admission characteristic groups and the mean values between deteriorated and non-deteriorated groups. Methods: From Jan. 2014 to Aug. 2017, medical records of mild TBI patients (Glasgow Coma Scale $\geq 13$ on arrival) were retrospectively reviewed. Admission characteristics and neurologic outcome of the first treatment week were analyzed. We compared the frequency of progressive deteriorated patients between independent variable groups and also mean value of admission characteristics between deteriorated and non-deteriorated groups. Results: The 193 patients were included in this study. 22 showed neurologic aggravation in the first treatment week. Subdural hematoma $(\mathrm{SDH} ; \mathrm{n}=82,42.5 \%)$ was the most frequent $\mathrm{CT}$ finding as main lesion. The thickness of epidural hematoma (EDH) or $\mathrm{SDH}$, midline shift and compression of basal cistern in the initial CT scan were significant factors of progressive deterioration, whereas the volume of intracranial hemorrhage $(\mathrm{ICH})$ showed no significance. In laboratory tests, deteriorated group had low hemoglobin $(\mathrm{Hb})$ level and higher white blood cell count. However, the initial vital signs didn't significantly affect the outcome. Conclusion: In this study, thickness of EDH or SDH in the initial CT scan, coagulopathy, leukocytosis, anemia showed to have effect on neurologic aggravation. Systolic blood pressure and body temperature, which have been considered important in managing severe TBI patients, showed no significance. However, because the difference is not large enough for clinical use, further studies are needed for verification.

Key Words: Brain injuries, traumatic; Clinical laboratory techniques; Intracranial hemorrhages; Prognosis

\section{INTRODUCTION}

Traumatic brain injury (TBI) is one of the leading cause of mortality and morbidity throughout the world and it is a major socioeconomic problem ${ }^{29)}$. Although the management for TBI has been evolving greatly with a long historical background, the 'heterogeneity of TBI' makes clinicians difficult to establish treatment strategy and to predict outcomes. However, studies about clinical course of acute mild TBI have been difficult to find in the literature as compared to active researches of severe TBI.

Predicting clinical course of acute mild TBI is important, in several point of view. The patient who shows progressive deterioration after good neurological status in the first examina- tion can be neglected by medical staffs or have more chance to be exposed to monitoring failure compared to those having poor mentality from the first, which may lead to miss the adequate time of neurosurgical and critical care interventions. Because the number of intensive care unit (ICU) beds and medical staff is scarce, we must decide whether these patients should be admitted to the ICU or general ward, or transfer to higher trauma center ${ }^{23,25)}$. In addition, preventing unnecessary ICU admission reduces cost and prevents potential adverse effect of ICU stay such as delirium and nosocomial infections ${ }^{17)}$.

The purpose of this study is to assess the rate of progressive mental deterioration of acute mild TBI patients with intracranial hemorrhage within first treatment week who had 6 points of Glasgow Coma Scale (GCS) motor score on arrival at the emer- 
gency room (ER), and to compare the deterioration frequency between categorized admission variable groups and the mean values between deteriorated and non-deteriorated groups.

\section{MATERIALS AND METHODS}

\section{Patients}

From January 2014 to August 2017, medical records of TBI patients who initially showed GCS 13 or more on arrival were collected. Among them, patients aged 15 years or more and with history of trauma within 1 week were included in the study. Patients without any traumatic intracranial hemorrhage and those having only linear skull fractures without intracranial lesions were excluded, because they rarely need hospitalization and neurosurgical interventions ${ }^{4,11,12,15,16,21,22)}$. The inclusion and exclusion criteria are as follows.

\section{Inclusion Criteria}

* Patients with 15 or more age.

* History of head trauma was less than 1 week.

* Patients with acute intracranial hemorrhage in first computed tomography (CT) scan.

* Patients who showed 13 or more GCS at first neurological examination at the ER.

* Patients who showed 6 points of GCS motor score at first.

* Patients who had been observed for 1 week or more.

\section{Exclusion Criteria}

* Patients who had been discharged from the ER or been immediately transferred to another center.

* Age below 15.

* Patients with head trauma history 1 week or more.

* Patients without acute intracranial hemorrhage in the first CT scan (with or without skull fracture).

* Patients who showed GCS less than 13 at first neurological examination.

* Patients who showed 5 or less points of GCS motor score at first examination.

* Patients who had been observed less than 1 week.

* Patients who underwent neurosurgical treatment before their neurological progression.

Their age, gender, past medical history (hypertension, diabetes, hematologic disorders, chronic liver diseases, chronic kidney diseases, presence of solid cancer, antiplatelet and anticoagulant medication), initial vital signs (systolic blood pressure $[\mathrm{SBP}]$, pulse rate $[\mathrm{PR}]$, respiratory rate [RR], body temperature [BT]), initial laboratory results (white blood cell [WBC] count, hemoglobin $[\mathrm{Hb}]$ level, platelet count $[\mathrm{PC}]$, prothrombin time [PT], activated partial thromboplastin time [aPTT]), first CT findings (type of hemorrhage, dominant hemorrhage type, dominant side, volume of hemorrhage, midline shift, presence of skull fracture, compression of basal cistern), initial GCS, injury to CT time and acute neurological outcome during the first treatment week were analyzed. Reduction of the GCS motor score was considered as symptomatic progression.

\section{Statistical Analysis}

Each independent variable was grouped to compare the frequency of exacerbated patients between groups. The grouping of each independent variable was made with the values shown in the Table 1. In addition, the mean values of the continuous variables of the deteriorated group and the non-deteriorated group were compared. Statistical analysis was performed with SAS/STAT ${ }^{\circledR}$ software (SAS Institute Inc., Cary, NC, USA) using $X^{2}$ or Fisher's exact test in frequency comparison and Wilcoxon's or $t$-test in the mean comparison, according to the type of the variables.

\section{RESULTS}

\section{Baseline Information of the Patients}

With above listed inclusion and exclusion criteria, 193 consecutive patients were included in the study. Among these patients, 22 patients (11.4\%) showed neurological aggravation in the first treatment week. Baseline information of the patients are described in Table 1 and mean values of each variables are in Table 2. Mean age was $64.89 \pm 17.36$ and 75 patients (38.9\%) were female. The 87 patients had hypertension and 51 had diabetes. Six patients had hematologic disorders. Two patients had chronic liver disease and 13 patients had chronic kidney disease. The 7 patients were under treatment of solid cancer. Forty-nine patients were having at least one antiplatelet agents and 5 patients were under anticoagulation. Mean GCS was $14.53 \pm 0.71$. Mean SBP, PR, RR, and BT on arrival were $141.30 \pm 23.37 \mathrm{mmHg}, 81.15 \pm 15.23 / \mathrm{min}, 18.39 \pm 2.72 / \mathrm{min}$, and $36.71 \pm 0.52^{\circ} \mathrm{C}$. Initial WBC count, $\mathrm{Hb}, \mathrm{PC}$, PT international normalized ratio [INR]), and aPTT were 8.175 $\pm 3.5410^{9} / \mathrm{L}, 232.54 \pm$ $76.0510^{9} / \mathrm{L}, 1.05 \pm 0.10$ and $27.86 \pm 7.73 \mathrm{sec}$. The mean time taken for CT scanning since trauma was $17.90 \pm 30.99(0.5-164)$ hr. Subdural hematoma (SDH; $n=82,42.5 \%$ ) was the most frequent CT finding as a main lesion followed by intracerebral hemorrhage (ICH; n=59, 30.6\%), subarachnoid hemorrhage (SAH; $n=31,16.1 \%)$, epidural hematoma (EDH; n=21, 10.9\%). Eightytwo patients had left side dominant lesion (42.5\%). Forty patients showed at least $1 \mathrm{~mm}$ of midline shift and 57 patients had concomitant skull fractures. Compressed basal cisterns were noted in 10 patients.

\section{Comparison of the Frequency of Deteriorated Patients between Independent Variable Groups}

We compared the frequency of progressive deteriorated patients between independent variable groups (Table 1). Male, GCS, WBC over $10.0 \times 10^{9} / \mathrm{L}, \mathrm{Hb}$ less than $12 \mathrm{~g} / \mathrm{dL}$, aPTT over $40 \mathrm{sec}$, presence of $\mathrm{SDH}$ or $\mathrm{SAH}$, thicker $\mathrm{EDH}$ or $\mathrm{SDH}$, more 
Table 1. Baseline characteristics of the patients and frequency comparison of deteriorated patients between independent variable categories

\begin{tabular}{|c|c|c|c|c|c|}
\hline Admission characteristics & Category & $\begin{array}{c}\text { All patients } \\
(\mathrm{n}=193) \\
\end{array}$ & $\begin{array}{c}\text { Deteriorated } \\
(\mathrm{n}=22)\end{array}$ & $\begin{array}{c}\text { Non-deteriorate } \\
d(n=171)\end{array}$ & p-value \\
\hline \multirow{2}{*}{ Age (year) } & $<65$ & $81(42.0)$ & $6(27.3)$ & 75 (43.9) & 0.138 \\
\hline & $\geq 65$ & $112(58.0)$ & $16(72.7)$ & $96(56.1)$ & \\
\hline \multirow[t]{2}{*}{ Sex } & Male & $118(61.1)$ & $18(81.8)$ & $100(58.5)$ & $0.035^{+}$ \\
\hline & Female & 75 (38.9) & 4 (18.2) & 71 (41.5) & \\
\hline \multicolumn{6}{|l|}{ History } \\
\hline \multirow[t]{2}{*}{ Hypertension } & Yes & $87(45.1)$ & $10(45.5)$ & $77(45.0)$ & 0.970 \\
\hline & No & $106(54.9)$ & $12(54.5)$ & $94(55.0)$ & \\
\hline \multirow[t]{2}{*}{ Diabetes } & Yes & $51(26.4)$ & $9(40.9)$ & $42(24.6)$ & 0.102 \\
\hline & No & $142(73.6)$ & $13(59.1)$ & $129(75.4)$ & \\
\hline \multirow[t]{2}{*}{ Hematologic disorder } & Yes & $6(3.1)$ & $1(4.5)$ & $5(2.9)$ & $0.521^{*}$ \\
\hline & No & $187(96.9)$ & $21(95.5)$ & $166(97.1)$ & \\
\hline \multirow[t]{2}{*}{ Chronic liver disease } & Yes & $2(1.0)$ & $0(0.0)$ & $2(1.2)$ & $1.000^{*}$ \\
\hline & No & $191(99.0)$ & $22(100.0)$ & $169(98.8)$ & \\
\hline \multirow[t]{2}{*}{ Chronic kidney disease } & Yes & $13(6.7)$ & $3(13.6)$ & $10(5.8)$ & $0.172^{*}$ \\
\hline & No & 180 (93.3) & 19 (86.4) & $161(94.2)$ & \\
\hline \multirow[t]{2}{*}{ Solid cancer } & Yes & $7(3.6)$ & $0(0.0)$ & $7(4.1)$ & $1.000^{*}$ \\
\hline & No & $186(96.4)$ & $22(100.0)$ & $164(95.9)$ & \\
\hline \multirow{2}{*}{ Antiplatelet agent } & Yes & $49(25.4)$ & $8(36.4)$ & $41(24.0)$ & 0.209 \\
\hline & No & $144(74.6)$ & $14(63.6)$ & $130(76.0)$ & \\
\hline \multirow[t]{2}{*}{ Anticoagulant } & Yes & $5(2.6)$ & $0(0.0)$ & $5(2.9)$ & $1.000^{*}$ \\
\hline & No & $188(97.4)$ & $22(100.0)$ & $166(97.1)$ & \\
\hline \multirow[t]{3}{*}{ Trauma to CT time } & $\leq 2$ & 75 (38.9) & $7(31.8)$ & $68(39.8)$ & 0.485 \\
\hline & $>2$ and $\leq 8$ & $50(25.9)$ & $8(36.4)$ & $42(24.6)$ & \\
\hline & $>8$ & $68(35.2)$ & $7(31.8)$ & 61 (35.7) & \\
\hline \multirow[t]{3}{*}{ GCS score } & 15 & $126(65.3)$ & $8(36.4)$ & $118(69.0)$ & $0.003^{*+}+$ \\
\hline & 14 & 43 (22.3) & $7(31.8)$ & $36(21.1)$ & \\
\hline & 13 & $24(12.4)$ & $7(31.8)$ & $17(9.9)$ & \\
\hline \multicolumn{6}{|l|}{ Vital signs } \\
\hline \multirow[t]{3}{*}{ Systolic blood pressure $(\mathrm{mmHg})$} & $\geq 140$ & $47(24.4)$ & $7(31.8)$ & $40(23.4)$ & 0.560 \\
\hline & $\geq 90$ and $<140$ & $136(70.5)$ & $13(59.1)$ & $123(71.9)$ & \\
\hline & $<90$ & $10(5.2)$ & $2(9.1)$ & $8(4.7)$ & \\
\hline \multirow{3}{*}{ Pulse rate (per min) } & $\geq 100$ & $27(14.0)$ & $5(22.7)$ & $22(12.9)$ & $0.339^{*}$ \\
\hline & $\geq 60$ and $<100$ & $158(81.9)$ & $16(72.7)$ & $142(83.0)$ & \\
\hline & $<60$ & $8(4.1)$ & $1(4.5)$ & $7(4.1)$ & \\
\hline \multirow{2}{*}{ Respiratory rate (per min) } & $\geq 20$ & $86(44.6)$ & $12(54.5)$ & 74 (43.3) & 0.317 \\
\hline & $<20$ & $107(55.4)$ & $10(45.5)$ & $97(56.7)$ & \\
\hline \multirow[t]{2}{*}{ Body temperature $\left({ }^{\circ} \mathrm{C}\right)$} & $\geq 37.5$ & $18(9.3)$ & $1(4.5)$ & $17(9.9)$ & $0.699^{*}$ \\
\hline & $<37.5$ & $175(90.7)$ & $21(95.5)$ & $154(90.1)$ & \\
\hline
\end{tabular}

CT: computed tomography; GCS: Glasgow Coma Scale; WBC: white blood cell; PT: prothrombin time; INR: international normalized ratio; aPTT: activated partial thromboplastin time; SDH: subdural hematoma; ICH: intracerebral hemorrhage; EDH: epidural hematoma; $\mathrm{SAH}$ : subarachnoid hemorrhage; $\mathrm{IVH}$ : intraventricular hemorrhage.

The data is presented as number (\%).

" $p$-value by Fisher's exact test. ${ }^{\dagger} p<0.05$.

62 www.thenerve.net 
Table 1. Baseline characteristics of the patients and frequency comparison of deteriorated patients between independent variable categories

\begin{tabular}{|c|c|c|c|c|c|}
\hline Admission characteristics & Category & $\begin{array}{c}\text { All patients } \\
(n=193)\end{array}$ & $\begin{array}{c}\text { Deteriorated } \\
(n=22)\end{array}$ & $\begin{array}{c}\text { Non-deteriorate } \\
d(n=171)\end{array}$ & p-value \\
\hline \multicolumn{6}{|l|}{ Laboratory findings } \\
\hline \multirow[t]{2}{*}{ WBC count $\left(10^{9} / \mathrm{L}\right)$} & $>10.0$ & $43(22.3)$ & $10(45.5)$ & $33(19.3)$ & $0.012^{*},+$ \\
\hline & $\leq 10.0$ & $150(77.7)$ & $12(54.5)$ & $138(80.7)$ & \\
\hline \multirow[t]{2}{*}{ Hemoglobin (g/dL) } & $\geq 12$ & $117(60.6)$ & $8(36.4)$ & $109(63.7)$ & $0.013^{+}$ \\
\hline & $<12$ & $76(39.4)$ & $14(63.6)$ & $62(36.3)$ & \\
\hline \multirow{3}{*}{ Platelet count $\left(10^{9} / \mathrm{L}\right)$} & $\geq 150$ & $171(88.6)$ & $19(86.4)$ & $152(88.9)$ & $0.063^{*}$ \\
\hline & $\geq 100$ and $<150$ & $18(9.3)$ & $1(4.5)$ & $17(9.9)$ & \\
\hline & $<100$ & $4(2.1)$ & $2(9.1)$ & $2(1.2)$ & \\
\hline \multirow{2}{*}{ PT (INR) } & $>1.2$ & $9(4.7)$ & $2(9.1)$ & $7(4.1)$ & $0.273^{*}$ \\
\hline & $\leq 1.2$ & $184(95.3)$ & $20(90.9)$ & $164(95.9)$ & \\
\hline \multirow[t]{2}{*}{ aPTT (sec) } & $>40$ & $7(3.6)$ & $4(18.2)$ & $3(1.8)$ & $0.004^{*},+$ \\
\hline & $\leq 40$ & $186(96.4)$ & $18(81.8)$ & $168(98.2)$ & \\
\hline \multicolumn{6}{|l|}{ CT findings } \\
\hline \multirow{5}{*}{ Hemorrhage type (if any) } & $\mathrm{SDH}$ & $116(60.1)$ & $21(95.5)$ & $95(55.6)$ & $<0.001^{+}$ \\
\hline & $\mathrm{ICH}$ & $81(42.0)$ & $12(54.5)$ & $69(40.4)$ & 0.204 \\
\hline & $\mathrm{EDH}$ & $26(13.5)$ & $3(13.6)$ & $23(13.5)$ & $1.000^{*}$ \\
\hline & SAH & $106(54.9)$ & $18(81.8)$ & $88(51.5)$ & $0.007^{+}$ \\
\hline & $\mathrm{IVH}$ & $2(1.0)$ & $0(0.0)$ & $2(1.2)$ & $1.000^{*}$ \\
\hline \multirow[t]{4}{*}{ Dominant lesion type } & $\mathrm{SDH}$ & $82(42.5)$ & $13(59.1)$ & $69(40.4)$ & $0.319^{*}$ \\
\hline & $\mathrm{ICH}$ & $59(30.6)$ & $6(27.3)$ & $53(31.0)$ & \\
\hline & $\mathrm{EDH}$ & $21(10.9)$ & $2(9.1)$ & $19(11.1)$ & \\
\hline & SAH & $31(16.1)$ & $1(4.5)$ & $30(17.5)$ & \\
\hline \multirow[t]{2}{*}{ Dominant side } & Right & $111(57.5)$ & $13(59.1)$ & $98(57.3)$ & 0.874 \\
\hline & Left & $82(42.5)$ & $9(40.9)$ & $73(42.7)$ & \\
\hline \multirow[t]{3}{*}{ Thickness of $\mathrm{EDH}$ or $\mathrm{SDH}(\mathrm{mm})$} & $>5$ & 64 (33.2) & $16(72.7)$ & $48(28.1)$ & $<0.001^{+}$ \\
\hline & $>0$ and $\leq 5$ & $66(34.2)$ & 4 (18.2) & $62(36.3)$ & \\
\hline & 0 & $63(32.6)$ & $2(9.1)$ & $61(35.7)$ & \\
\hline \multirow{3}{*}{ Volume of $\mathrm{ICH}(\mathrm{cc})$} & $>10$ & $10(5.2)$ & $2(9.1)$ & $8(4.7)$ & 0.361 \\
\hline & $>0$ and $\leq 10$ & $70(36.3)$ & $10(45.5)$ & $60(35.1)$ & \\
\hline & 0 & $113(58.5)$ & $0(0.0)$ & $113(66.1)$ & \\
\hline \multirow[t]{3}{*}{ Midline shift (mm) } & $>5$ & $10(5.2)$ & $6(27.3)$ & $4(2.3)$ & $<0.001^{*},+$ \\
\hline & $>0$ and $\leq 5$ & $30(15.5)$ & $7(31.8)$ & $23(13.5)$ & \\
\hline & 0 & 153 (79.3) & $9(40.9)$ & 144 (84.2) & \\
\hline \multirow[t]{2}{*}{ Skull fracture } & Yes & $57(29.5)$ & $7(31.8)$ & $50(29.2)$ & 0.803 \\
\hline & No & $136(70.5)$ & $15(68.2)$ & $121(70.8)$ & \\
\hline \multirow[t]{2}{*}{ Compression of basal cisterns } & Yes & $10(5.2)$ & $9(40.9)$ & $1(0.6)$ & $<0.00^{1 *++}$ \\
\hline & No & 183 (94.8) & $13(59.1)$ & $170(99.4)$ & \\
\hline
\end{tabular}

CT: computed tomography; GCS: Glasgow Coma Scale; WBC: white blood cell; PT: prothrombin time; INR: international normalized ratio; aPTT: activated partial thromboplastin time; $\mathrm{SDH}$ : subdural hematoma; $\mathrm{ICH}$ : intracerebral hemorrhage; $\mathrm{EDH}$ : epidural hematoma; SAH: subarachnoid hemorrhage; IVH: intraventricular hemorrhage.

The data is presented as number (\%).

${ }^{*} \mathrm{p}$-value by Fisher's exact test. $+p<0.05$. 
midline shift, compression of basal cistern were statistically related to increment of frequency of aggravated patients. Whereas, the age 65 or more, past medical history (antiplatelet agent, anticoagulation, hypertension, diabetes, chronic kidney disease, chronic liver disease, solid cancer, hematologic disease), initial vital signs ( $\mathrm{SBP} \geq 140 \mathrm{mmHg}$, PR $\geq 100 / \mathrm{min}, \mathrm{RR} \geq 20 / \mathrm{min}$, BT $\geq 37.5^{\circ} \mathrm{C}$ ), PC (groups: below 100, 100 or below 150, 150 or more $10 \%$ L), PT INR over 1.2 caused no significant differences. In addition, the dominant lesion type (groups: SDH, SAH, ICH, $\mathrm{EDH}$, intraventricular hemorrhage [IVH]), left side dominant lesion, presence of EDH or ICH or IVH, volume of ICH (groups: 0,10 or below, over $10 \mathrm{cc}$ ) and skull fractures in the first CT scan were not statistically increased frequency of deterioration.

\section{Mean Comparison of Admission Characteristics between Deteriorated and Non-deteriorated Groups}

The comparison of mean value of continuous variables between 2 groups is described in Table 2 . The neurologically non-deteriorated group showed lower age $(\mathrm{p}=0.025)$, higher initial GCS ( $\mathrm{p}=0.001)$, lower WBC count $(\mathrm{p}<0.004)$, higher $\mathrm{Hb}$ level $(p=0.006)$, lower PT INR $(p<0.001)$, less thickness of EDH or SDH $(p<0.001)$, less midline shift $(p<0.001)$ compared to the mean values of deteriorated group. The SBP, PR, RR, BT, PC, aPTT, first CT time, and volume of ICH were not statistically different between 2 groups.

\section{DISCUSSION}

A mild TBI is a common injury that clinicians encounter very often in the $\mathrm{ER}^{1)}$. A $6 \%$ to $12 \%$ of them shows intracranial abnormality and they are called complicated mild $\mathrm{TBI}^{(, 24)}$. However, according to the previous reports, only $0.13 \%$ to $0.3 \%$ of mild TBI needs neurosurgical interventions ${ }^{3,4,7,14,16)}$. In a systematic review by Stippler et al. ${ }^{27)}$, additional brain CT taken after the neurological deterioration (11/1594, 0.7\%) led to more frequent neurosurgical intervention than routine follow up CT scanning $(24 / 56,42.9 \%)$. Therefore, patients' neurological status mainly affects the treatment strategy for mild TBI. In addition, even if the patient does not have lesions requiring neurosurgical interventions, the patient may need airway management or non-surgical critical care during the neurologically deteriorated period.

We observed 193 consecutive mild TBI patients with acute ICH in the initial CT scan. The 22 patients (11.4\%) showed progressive neurological aggravation, defined as decline of GCS motor score in this study, in their first treatment week. According to Stippler et al. ${ }^{27}$, systematic review of 19 previous publications, only 56 of 1,630 patients (3.4\%) showed neurological decline which was quite lower than the frequency of this study. This is probably due to the reason that we included patients with acute intracranial hemorrhage and excluded cases only with skull fractures or pneumocephalus without bleeding.

The risk factors, according to the literatures, for clinical deterioration after mild TBI includes low initial GCS, coagulopathy, a skull fracture crossing a major sinus or the middle meningeal artery and age over $65^{2,5,8,9,28)}$. According to the frequency analysis of this study, male sex, WBC over $10.0 \times$ $10^{9} / \mathrm{L}$, Hb less than $12 \mathrm{~g} / \mathrm{dL}$, aPTT over $40 \mathrm{sec}$, presence of $\mathrm{SDH}$ or $\mathrm{SAH}$, larger thickness of $\mathrm{EDH}$ or $\mathrm{SDH}$, more midline

Table 2. Mean comparison between deteriorated and non-deteriorated groups

\begin{tabular}{|c|c|c|c|c|c|}
\hline Admission characteristics & All patients ( $n=193)$ & Non-deteriorated $(n=171)$ & Deteriorated $(n=22)$ & Statistics & p-value \\
\hline Age (year) & 64.89 & 63.94 & 72.23 & Wilcoxon & $0.025^{*}$ \\
\hline GCS score & 14.53 & 14.59 & 14.05 & Wilcoxon & $0.001^{*}$ \\
\hline Systolic blood pressure $(\mathrm{mmHg})$ & 141.30 & 141.26 & 141.55 & T-test & 0.958 \\
\hline Pulse rate (per min) & 81.15 & 80.77 & 84.09 & Wilcoxon & 0.415 \\
\hline Respiratory rate (per min) & 18.39 & 18.33 & 18.86 & Wilcoxon & 0.393 \\
\hline Body temperature $\left({ }^{\circ} \mathrm{C}\right)$ & 36.72 & 36.73 & 36.60 & Wilcoxon & 0.486 \\
\hline WBC count $\left(10^{9} / L\right)$ & 8.18 & 7.83 & 10.82 & Wilcoxon & $0.004^{*}$ \\
\hline Hemoglobin (g/dL) & 12.55 & 12.66 & 11.62 & T-test & $0.006^{*}$ \\
\hline Platelet count $\left(10^{9} / \mathrm{L}\right)$ & 232.54 & 228.05 & 267.46 & T-test & 0.150 \\
\hline PT (INR) & 1.05 & 1.04 & 1.12 & Wilcoxon & $<0.001^{*}$ \\
\hline aPTT & 27.86 & 27.49 & 30.73 & Wilcoxon & 0.119 \\
\hline Trauma to CT time (hour) & 17.90 & 18.54 & 12.91 & Wilcoxon & 0.796 \\
\hline Thickness of EDH or SDH (mm) & 4.72 & 4.24 & 8.48 & Wilcoxon & $<0.001^{*}$ \\
\hline Volume of ICH (cc) & 3.02 & 2.89 & 4.00 & Wilcoxon & 0.138 \\
\hline Midline shift (mm) & 0.84 & 0.53 & 3.27 & Wilcoxon & $<0.001^{*}$ \\
\hline
\end{tabular}

GCS: Glasgow Coma Scale; WBC: white blood cell; PT: prothrombin time; INR: international normalized ratio; aPTT: activated partial thromboplastin time; $\mathrm{CT}$ : computed tomography; $\mathrm{EDH}$ : epidural hematoma; $\mathrm{SDH}$ : subdural hematoma; ICH: intracerebral hemorrhage. $\mathrm{p}<0.05$. 
shift, compression of basal cistern were statistically related to increment of frequency of aggravated patients (Table 1). In the mean value comparison, the neurologically non-deteriorated group showed lower age, higher initial GCS, lower WBC count, higher $\mathrm{Hb}$ level, lower PT INR, less volume of $\mathrm{EDH}$ or $\mathrm{SDH}$, less midline shift compared to the mean values of deteriorated group (Table 2).

The findings of the initial CT scan significantly affected progressive deterioration of the patient in this study. Especially, the mass effect by EDH or SDH was associated with the deterioration of the patient, whereas the volume of $\mathrm{ICH}$ showed no significance. These results are consistent with previous literatures on CT that predicts the prognosis of trauma patients $^{13,18,26,30)}$.

Among the initial laboratory findings, in addition to coagulopathy known from previous literature, hemoglobin and WBC count were also affected the neurologic prognosis for one week in the acute mild TBI patients ${ }^{5,8,28)}$. Anemia has been known to be associated with the prognosis of patients with severe TBI from previous literature, and also with poor neurological outcomes in ischemic stroke and SAH patients ${ }^{10)}$. In the meantime, literatures on the relationship between clinical course and hemoglobin level of mild TBI have been difficult to find, but the results of our study showed that anemia in acute mild TBI can adversely affect early neurological outcome. This suggest that oxygen delivery may be an important factor in patients with acute mild TBI, as in patients with severe TBI. WBC counts also showed statistically significant differences in both group frequency analysis and mean comparison. However, despite the statistically significant differences in mean $\mathrm{Hb}$ between the two groups, it is unlikely that there would be an enough difference (12.66-11.62 g/dL) to be applied to clinical practice.

The post-traumatic leukocytosis is known to be caused by increased catabolic hormones and cytokines, and eventually, increased leukocytes cause cerebral damage by occlusion and rupture of microvessels after WBC adherence to endothelium and aggregation to each other ${ }^{19,20)}$. In addition, they secretes cytotoxic mediators that causes additional brain damage ${ }^{19)}$. The result of this study shows that these mechanisms can be applied to patients with acute mild TBI with intracranial hemorrhage.

The initial vital signs, unlike other variables, did not show any statistically significant influence in both analysis. Managing intracranial pressure (ICP) and maintaining the adequate cerebral perfusion pressure (CPP) are essential in treating brain injury and determining the optimal level of ICP and CPP is a very active research topic in severe TBI management in recent decades ${ }^{20)}$. In addition, what is the proper body temperature and how to maintain it, is also an important issue for ICP control. However, SBP, PR, RR, and BT do not seem to affect the early outcome in acute mild TBI patients.

This study has several limitations. It is a retrospective analysis of single center with small number of patients and the long- term outcome is not included. In addition, only decline of GCS motor score was considered as symptomatic aggravation, whereas focal neurologic deficits such as motor weakness and speech disturbance were not investigated.

\section{CONCLUSION}

In our study, progressive mental deterioration of mild TBI patients with acute intracranial hemorrhage was not rare (11.4\%). The mass effect of EDH or SDH in the initial CT scan and leukocytosis, anemia as well as coagulopathy in the laboratory tests showed to have effect on symptomatic aggravation. The vital signs such as SBP and BT, considered to be important in managing severe TBI, showed no significance on early outcome in acute mild TBI patients. However, even though there are factors showing statistically significance in this study, it is difficult to say that it has large enough differences, especially the $\mathrm{Hb}$, to apply them in real clinical practice. Additional multicenter, randomized, prospective studies with larger case series are needed in the future.

\section{CONFLICT OF INTEREST}

No potential conflict of interest relevant to this article was reported.

\section{REFERENCES}

1. Cassidy JD, Carroll LJ, Peloso PM, Borg J, von Holst H, Holm $\mathrm{L}$, et al.: Incidence, risk factors and prevention of mild traumatic brain injury: results of the WHO collaborating centre task force on mild traumatic brain injury. J Rehabil Med :28-60, 2004

2. Chieregato A, Fainardi E, Morselli-Labate AM, Antonelli V, Compagnone C, Targa L, et al.: Factors associated with neurological outcome and lesion progression in traumatic subarachnoid hemorrhage patients. Neurosurgery 56:671-680, 2005

3. Fabbri A, Servadei F, Marchesini G, Morselli-Labate AM, Dente $\mathrm{M}$, Iervese T, et al.: Prospective validation of a proposal for diagnosis and management of patients attending the emergency department for mild head injury. J Neurol Neurosurg Psychiatry 75:410-416, 2004

4. Haydel MJ, Preston CA, Mills TJ, Luber S, Blaudeau E, DeBlieux PM: Indications for computed tomography in patients with minor head injury. N Engl J Med 343:100-105, 2000

5. Hollingworth W, Vavilala MS, Jarvik JG, Chaudhry S, Johnston BD, Layman S, et al.: The use of repeated head computed tomography in pediatric blunt head trauma: factors predicting new and worsening brain injury. Pediatr Crit Care Med 8:348-356; CEU quiz 357, 2007

6. Ibañez J, Arikan F, Pedraza S, Sanchez E, Poca MA, Rodriguez $\mathrm{D}$, et al.: Reliability of clinical guidelines in the detection of patients at risk following mild head injury: results of a prospec- 
tive study. J Neurosurg 100:825-834, 2004

7. Jeret JS, Mandell M, Anziska B, Lipitz M, Vilceus AP, Ware JA, et al.: Clinical predictors of abnormality disclosed by computed tomography after mild head trauma. Neurosurgery 32:9-15, 1993

8. Kaufman HH, Moake JL, Olson JD, Miner ME, duCret RP, Pruessner JL, et al.: Delayed and recurrent intracranial hematomas related to disseminated intravascular clotting and fibrinolysis in head injury. Neurosurgery 7:445-449, 1980

9. Knuckey NW, Gelbard S, Epstein MH: The management of "asymptomatic" epidural hematomas. a prospective study. J Neurosurg 70:392-396, 1989

10. Lelubre C, Bouzat P, Crippa IA, Taccone FS: Anemia management after acute brain injury. Crit Care 20:152, 2016

11. Livingston DH, Lavery RF, Passannante MR, Skurnick JH, Baker S, Fabian TC, et al.: Emergency department discharge of patients with a negative cranial computed tomography scan after minimal head injury. Ann Surg 232:126-132, 2000

12. Livingston DH, Loder PA, Hunt CD: Minimal head injury: is admission necessary? Am Surg 57:14-17, 1991

13. Maas AI, Hukkelhoven CW, Marshall LF, Steyerberg EW: Prediction of outcome in traumatic brain injury with computed tomographic characteristics: a comparison between the computed tomographic classification and combinations of computed tomographic predictors. Neurosurgery 57:1173-1182; discussion 11731182, 2005

14. Miller EC, Derlet RW, Kinser D: Minor head trauma: Is computed tomography always necessary? Ann Emerg Med 27:290294, 1996

15. Moran SG, McCarthy MC, Uddin DE, Poelstra RJ: Predictors of positive CT scans in the trauma patient with minor head injury. Am Surg 60:533-535, 1994

16. Nagy KK, Joseph KT, Krosner SM, Roberts RR, Leslie CL, Dufty K, et al.: The utility of head computed tomography after minimal head injury. J Trauma 46:268-270, 1999

17. Norris C, Jacobs P, Rapoport J, Hamilton S: ICU and non-ICU cost per day. Can J Anaesth 42:192-196, 1995

18. Raj R, Siironen J, Skrifvars MB, Hernesniemi J, Kivisaari R: Predicting outcome in traumatic brain injury: development of a novel computerized tomography classification system (Helsinki computerized tomography score). Neurosurgery 75:632-646, 2014

19. Rovlias A, Kotsou S: The blood leukocyte count and its progno- stic significance in severe head injury. Surg Neurol 55:190-196, 2001

20. Schmid-Schönbein GW: Capillary plugging by granulocytes and the no-reflow phenomenon in the microcirculation. Fed Proc 46:2397-2401, 1987

21. Seddighi AS, Motiei-Langroudi R, Sadeghian H, Moudi M, Zali A, Asheghi E, et al.: Factors predicting early deterioration in mild brain trauma: a prospective study. Brain Inj 27:1666-1670, 2013

22. Sifri ZC, Homnick AT, Vaynman A, Lavery R, Liao W, Mohr A, et al.: A prospective evaluation of the value of repeat cranial computed tomography in patients with minimal head injury and an intracranial bleed. J Trauma 61:862-867, 2006

23. Sinuff T, Kahnamoui K, Cook DJ, Luce JM, Levy MM: Rationing critical care beds: a systematic review. Crit Care Med 32: 1588-1597, 2004

24. Smits M, Dippel DW, de Haan GG, Dekker HM, Vos PE, Kool DR, et al.: External validation of the Canadian CT head rule and the new orleans criteria for CT scanning in patients with minor head injury. JAMA 294:1519-1525, 2005

25. Stelfox HT, Hemmelgarn BR, Bagshaw SM, Gao S, Doig CJ, Nijssen-Jordan C, et al.: Intensive care unit bed availability and outcomes for hospitalized patients with sudden clinical deterioration. Arch Intern Med 172:467-474, 2012

26. Steyerberg EW, Mushkudiani N, Perel P, Butcher I, Lu J, McHugh GS, et al.: Predicting outcome after traumatic brain injury: development and international validation of prognostic scores based on admission characteristics. PLoS Med 5:e165, 2008

27. Stippler M, Smith C, McLean AR, Carlson A, Morley S, MurrayKrezan C, et al.: Utility of routine follow-up head CT scanning after mild traumatic brain injury: a systematic review of the literature. Emerg Med J 29:528-532, 2012

28. The Study Group on Head Injury of the Italian Society for Neurosurgery: Guidelines for minor head injured patients' manage ment in adult age. J Neurosurg Sci 40:11-15, 1996

29. Thurman DJ, Alverson C, Dunn KA, Guerrero J, Sniezek JE: Traumatic brain injury in the United States: A public health perspective. J Head Trauma Rehabil 14:602-615, 1999

30. Yuh EL, Cooper SR, Ferguson AR, Manley GT: Quantitative CT improves outcome prediction in acute traumatic brain injury. $\mathrm{J}$ Neurotrauma 29:735-746, 2012 